\title{
Tips and Tricks for a More Effective You: Lessons Learned From a USAFA Cadet
}

\section{Mr. Alexander Samaniego, United States Air Force}

Alexander is a second class cadet at the United States Air Force Academy, originally from San Diego, $\mathrm{CA}$, who is working towards a bachelors of science in systems engineering.

\section{Martin Span III, United States Air Force}

Trae is the Deputy Director of the Systems Engineering Program and Instructor of Systems Engineering at the United States Air Force Academy (USAFA), Colorado Springs, Colorado. He is commissioned as Captain in the United States Air Force (USAF). In his role as Deputy Director, he supports over 230 cadets in the ABET accredited systems engineering major. Systems Engineering is currently the largest engineering major at USAFA, administered by seven departments with cadets participating in over 30 engineering capstones projects. Trae received his undergraduate degree in Systems Engineering in 2012 from USAFA with a focus in Electrical Engineering. He is a distinguished graduate from the Air Force Institute of Technology receiving a Master of Science in Systems Engineering in 2018. Trae serves in the USAF as a developmental engineer and holds Department of Defense certifications in systems engineering, science and technology management, test \& evaluation, and program management. He has served the USAF as a developmental test engineer responsible for planning and executing complex weapon system test and evaluation. He is a member of IEEE and the Tau Beta Pi honor society. 


\section{Tips and Tricks for a More Effective You: Lessons \\ Learned From a USAFA Cadet}

Introduction:

Established as a means of preparing students to serve as officers in the Air Force, the United States Air Force Academy (USAFA) focuses on developing well-rounded leaders who are charged with excelling in a military environment. This objective is achieved by focusing on the idea of a well-rounded person, as cadets are not only expected to excel in a rigorous academic environment but must also excel in regards to military and physical training. In order to excel in this type of environment, cadets must develop simple yet effective methods to ensure success. Additionally, a positive feedback system is necessary in order for the student to be able to ensure their chosen methods are working. Although the title of this paper insinuates that these tips are independent of one another, in reality, they are used in conjunction to achieve one goal, to not only succeed in any undergraduate program but to excel. Using the systems engineering SAE loop as the framework, this method will initiate with the analysis of a student's given situation, the formulation of a plan of action, the utilization of effective study habits, and end with the significance of mentors in the student's plan.

\section{SAE Loop:}

In order to provide a positive feedback system for the students utilizing these methods, as well as an iterative model that can be adjusted as necessary, the systems engineering synthesis, analysis, and evaluation (SAE) loop will be used. Under the synthesis phase, the 
needs that must be met in accordance with customer requirements, or in this case student requirements are evaluated. In this paper, the analysis of the student's situation will fall under this phase. This will be followed by the analysis phase, which is used to acquire the necessary data upon which the determined methods can be properly evaluated to determine if they are indeed effective. After these two steps are done, the evaluation step will check to see if the customer requirements are being met, using the data collected as well as customer input. In this case, the student will evaluate their chosen methods and then determine if they should continue the course they are on or should instead make any necessary changes. [1]

Synthesis:

To understand a cadet's perspective, it is first important to understand the circumstance of the environment in which they live. In the case of cadets at USAFA, it is important to note that a grade point average is not the only grading metric used, but is instead one of three. Cadets also receive cumulative grades based on their physical and military performance, which is important to note as it describes the level of commitment required of each cadet. Therefore in order to be successful at USAFA cadets must learn to balance academics, physical fitness, and military training. These distinct factors demonstrate that regardless of their own personal circumstances, all cadets are held to the same standards. A student at another university, however, would have no problem utilizing these tips to succeed, as there are many similarities between cadets and university students. In much the same way that cadets have to balance their schedules in order to succeed in each of the three grading criteria, university students must likewise learn to balance their schedules. Apart from classes, many 
students may have other factors to consider such as work, athletics, or other responsibilities at home. In this way, it becomes apparent that although both lead very different lives, the importance of time management is crucial. This requirement, however, only takes required activities into account, and fails to include additional activities, such as maintaining an active social life and ensuring proper rest, two additional requirements that take up a student's time.

Analysis:

As it is understood that time is the main limiting factor, students beginning an undergraduate program must analyze the rigors of the major they are choosing, combined with their extracurricular activities and other responsibilities. It might take multiple lessons to figure this out, but students must learn to prioritize tasks they believe to be most important, whether it be academic, athletic, or even their social life. This is crucial as it will ensure that the student succeeds while still meeting their given requirements. For example, if having a social life and participating in extracurricular activities is incredibly important to a given student, a demanding major such as physics will require the student to give up more time to succeed, ultimately going against the high significance on social life they had set for themselves. As the SAE Loop is iterative, this step, like the others, can frequently be referenced and changed as needed. Then, if a student's needs change or they decided to reprioritize tasks, they can reorient their schedule to reflect their new priorities.

Evaluation: 
Following the synthesis and analysis tasks, students must use the requirements and priorities they determined in order to utilize effective study habits. This is known as the evaluation phase. In the synthesis phase, it became apparent that time was a major constraint. Due to this students must be aware of the fact that they should only take on activities and work they believe they will be able to effectively complete. Taking on too much will not only lead to a decrease in performance across all of the tasks but will also lead to added unnecessary stress. For these reasons, it is vital to the success of the student to create a plan that takes in important system requirements and prioritizes work to achieve mission completion. Initially, this might seem like a waste of time, given the fact that the initial demand will be incredibly low. It might even seem counterintuitive to spend extra time making a schedule when that time could have instead been spent completing tasks. However, once demand increases and the amount of activities likewise increases, having a plan to constantly reference ensures that the student always keeps their attention where it matters. In the case of cadets at USAFA, planning consists of creating schedules, whether weekly monthly or daily, and then prioritizing tasks in order of importance.

For example, if a student had three assignments due in one week, with their schedule they would know when each one was due, the level of importance of that assignment, and the amount of time needed to dedicate to those assignments. By doing this, a student will also be able to see what available time they have to accommodate for other activities they wish to participate in, but might not go towards the overall goal, which in the case of cadets is to graduate. The reason this is so important, as I have personally learned, is because it always ensures the students first completes tasks that go toward the main goal they set. If all 
important tasks are taken care of first, it not only provides peace of mind but also continually focuses the students' attention on their main goal, reducing the effect of distractions. If students find themselves unable to complete all of the tasks they set for themselves, then they can use this iterative process to go back and see where the issue lies. Then the student will be able to make changes based off of what did not previously work in the first iteration of their plan and improve it.

In order for the schedule to work, however, students must follow effective studying habits. Without this, even if they manage to plan out all of the tasks that must be completed, they could very well take too much time to complete a task or even do it incorrectly. The first step any student should take before beginning a task is to read the instructions to make sure that they are completing it in the right manner. As obvious as it may sound, failing to do so could lead to wasting time incorrectly working on the project, or failing to leave out crucial details that are specifically required. The next trick to working on any assignment is to follow the Pomodoro technique. This technique states that studying should be broken up into 25minute increments separated by 5 -minute breaks. After every studying session the student puts a tally down, and after 5 tallies are reached the student can then proceed to take a 15-minute break. Many cadets have found success using this technique as it forces them to focus on their work for short periods of time, while still providing breaks to relax and refresh before continuing to work. [2]

\section{Mentors:}


When used in conjunction, the aforementioned steps serve to help students' establish the goals they wish to accomplish, then provide the techniques necessary to complete those goals. However, these tricks rely solely on the student themselves. As is commonly known, many great accomplishments are not undertaken by a single person, but instead by a team. For this reason, the last step necessary to excel in any undergraduate program is to find a mentor. A mentor not only serves to keep the student accountable to the plan of action they have set but also serves to provide an avenue of new ideas the student would not have come up with. With greater experience and knowledge, mentors can help students see problems from different perspectives, and help them through the difficult life decisions they will be making. Among all of the tips in this piece finding a mentor is easily the most difficult, yet also the most rewarding. Students need not force a relationship, but can instead allow it to grow organically with connections they already have. However, in order to be successful two points must be followed. First, students should find a mentor that is in the situation they aspire to be in, so they can learn how to get there. Secondly, the mentor should be made aware of the student's goals, as not being informed would make it very difficult to keep the student accountable if they do not know what the student is striving to achieve.

Conclusion:

While cadets at the United States Air Force Academy have unique institutional requirements, cadets and other undergraduate students share one important overarching issue, they both face time constraints which affect every aspect of their lives. By determining personal requirements or constraints, analyzing the situation, and evaluating these methods to 
form an effective plan, cadets have proved that this method is effective in excelling in their environment. That is why utilizing the SAE Loop in the steps above is applicable to students at any institution. It does not focus on changing the environment the student is in, but instead of preparing students' to properly handle any situation they are in. 


\section{References}

[1] J. J. W. Buis, G. Post, V. R. Visser, Academic Skills for Interdisciplinary Studies. Amsterdam, Netherlands: Amsterdam University Press, 2016.

[2] F. Cirillo. The Pomodoro Technique. Random House UK, 2018. 